\title{
El formato Aula-Taller en primaria. Incidencia en la motivación y logros de aprendizaje de los estudiantes
}

\author{
Classroom-Workshop format in Elementary school. \\ Impact on students' motivation and their learning achievements
}

Metodologias ativas de ensino na sala de aula nos anos iniciais. Impacto
na motivação e nas realizações da aprendizagem do aluno

ISSN 1688-9304 - DOI: 10.18861/cied.2020.11.2.2982

Nancy Núñez Soler ${ }^{1 *}$

https://orcid.org/0000-0002-4665-4355

Mariela Lourdes González ${ }^{2 *}$

https://orcid.org/0000-0002-2649-1579

Fecha de recibido: 27/07/2019

Fecha de aprobado: 23/12/2019

\section{Resumen}

La mejora de la calidad educativa ha sido uno de los aspectos sobre los cuales la comunidad académica uruguaya ha puesto sus mayores esfuerzos. Sin embargo, los resultados de aprendizaje obtenidos por los estudiantes no están en relación con los esfuerzos realizados. La escuela tradicional no da hoy respuestas a las demandas de los alumnos, quienes no encuentran motivación en las aulas. El objetivo de esta investigación es analizar la influencia del formato Taller en la motivación y en la mejora de los logros de aprendizaje de los estudiantes de nivel primario. Se puso en práctica una metodología mixta con un enfoque secuencial comparativo sobre una población de 172 alumnos de $4 .^{\circ}$ a $6 .^{\circ}$ grado, en una franja etaria de entre 10 y 14 años en dos escuelas de Paysandú (Uruguay). Se optó por un diseño cuasi-experimental con grupo control con metodologías pedagógicas tradicionales y otro experimental con la innovación de Talleres. Dos tests fueron aplicados a los estudiantes: el Diagnóstico Integral de Estudio (DIE I) y el Inventario de Estilos de Aprendizaje (ILS) y a los docentes, por su parte, el Cuestionario de Dilemas sobre la Enseñanza y el Aprendizaje y un análisis de documentos impresos. Concluimos que la participación activa del niño como sujeto de su aprendizaje en escenarios lúdicos mejora la actitud ante el estudio, motiva y ayuda a comenzar el proceso de autorregulación y optimiza el rendimiento escolar. Por lo antedicho se visibiliza la necesidad de modificar formatos escolares tradicionales. El formato se presenta como una experiencia que trasciende el modelo lineal, que organiza el tiempo y el espacio en forma universal y que promueve el encuentro y el intercambio de saberes. El nuevo formato impacta también en los docentes, quienes deben organizar su propuesta didáctica con una configuración más creativa para atender las necesidades reales de sus alumnos.

Palabras clave: método pedagógico, taller, motivación, aprendizaje profundo, autorregulación. 


\begin{abstract}
The improvement of the quality of education has been one of the issues the Uruguayan academic community has put most effort into. However, the learning outcomes from students bear little relation with the efforts devoted. Today, the traditional schools fail to meet the students' expectations and thence learners lose motivation in the classroom. The objective of the present research is to analyze the influence of the Workshop format on both motivation and improvement of learning achievements by elementary students. A mixed methodology was implemented with a sequential comparative approach on a population of 172 students from grades 4-6, ranging from ages 10 to 14, at two schools in the locality of Paysandú (Uruguay). A quasi-experimental design was implemented: a control group with which traditional pedagogical methodologies were used and an experimental one, with the innovation of Workshop format. Students were subjected to two tests: a Comprehensive Study Diagnosis (DIE I) and an Inventory of Learning Styles (ILS), while teachers were subjected to a Dilemmas Questionnaire on Teaching and Learning and an Analysis of printed documents. The conclusion was that the children's active participation in game-like scenarios improves their attitude towards study and, at the same time, has a boosting effect on their motivation. Furthermore, the former facilitates the self-regulation process and optimizes school performance. Therefore, there is a clear need for redesigning the traditional school formats. Conceived as an experience that goes beyond the linear model, the new format organizes time and space universally, promoting the encounter and the exchange of knowledge. Besides, this new format has good impact on teachers too, who must organize their teaching practices with a more creative configuration to meet the real needs of their students.
\end{abstract}

Keywords: pedagogical method, workshop, motivation, deep learning, self-regulation.

\title{
Resumo
}

A melhoria da qualidade educacional tem sido um dos aspectos em que a comunidade acadêmica uruguaia tem se empenhado mais. No entanto, os resultados de aprendizagem obtidos pelos alunos não estão relacionados aos esforços realizados. Hoje, a escola tradicional não responde às demandas dos alunos que não encontram motivação na sala de aula. O objetivo desta pesquisa é analisar a influência do formato do Workshop na motivação e na melhoria dos resultados de aprendizagem dos alunos do ensino fundamental. Uma metodologia mista foi implementada com uma abordagem comparativa sequencial em uma população de 172 alunos de $4^{a}$ a $6^{a}$ série, na faixa etária de 10 a 14 anos, em duas escolas de Paysandú (Uruguai). Foi escolhido um desenho quase experimental com um grupo de controle com metodologias pedagógicas tradicionais e um projeto experimental com inovação em Workshop. Foram aplicados dois testes aos alunos, Diagnóstico de Estudo Abrangente (DIE I) e Inventário de Estilos de Aprendizagem (ILS) e aos professores, Questionário de Dilemas sobre Ensino e Aprendizagem e Análise de documentos impressos. Concluímos que a participação ativa da criança como objeto de sua aprendizagem em cenários lúdicos, melhora a atitude em relação ao estudo, motiva, ajuda a iniciar o processo de autorregulação e aperfeiçoa o desempenho escolar. Portanto, torna-se visível a necessidade de modificar os formatos escolares tradicionais. O formato é apresentado como uma experiência que transcende o modelo linear, que organiza o tempo e o espaço universalmente, o que promove o encontro e a troca de conhecimentos. O novo formato também afeta os professores, que devem organizar sua proposta de ensino com uma configuração mais criativa para atender às reais necessidades de seus alunos.

Palavras-chave: método pedagógico, metodologias ativas, motivação, aprendizagem profunda, autorregulação. 


\section{Introducción}

En Uruguay los esfuerzos académicos y las inversiones fiscales de los últimos treinta años están muy lejos de dar los resultados deseados. Los alumnos han descendido en sus aprendizajes, tal como lo evidencian los datos estadísticos de pruebas internacionales como PISA (Programa para la Evaluación Internacional de Alumnos) o regionales como TERCE (Tercer Estudio Regional Comparativo y Explicativo).

Los resultados de aprendizaje de las pruebas PISA 2015 indican que de los jóvenes uruguayos de 15 años que cursan enseñanza media, y por ende han transitado por toda la enseñanza primaria, algo menos del 30\% puede ubicar información directa y explícita en un texto, realizar sencillas inferencias e identificar el tema global pero no puede establecer relaciones del mismo texto con situaciones cotidianas ni identificar aspectos implícitos o interpretarlos críticamente.

En los resultados presentados de la evaluación de TERCE del año 2015 se especifica que el $79,9 \%$ de los niños uruguayos de $6 .^{\circ}$ año es incapaz de inferir el significado de palabras utilizadas con significados diversos dependiendo del contexto en el que se usan, no reflexiona sobre la función y los recursos de un texto ni relaciona dos textos a partir de sus propósitos comunicativos. Estos resultados, sin dudas, afectan la credibilidad en cuanto a la calidad de la educación pública en nuestro país. Pero hay otro dato que también preocupa y es el alto porcentaje de deserción al finalizar primaria, así como los pocos alumnos que logran finalizar enseñanza media. De acuerdo con los datos de Unesco, en 2010 Uruguay se ubicaba en el lugar más bajo de América Latina y el Caribe con respecto a la tasa neta de matriculación en enseñanza media. Otro tanto sucedía con la tasa de transición de primaria a secundaria. A pesar de los esfuerzos realizados para revertir esta situación, las tendencias al 2018 no se han modificado sustancialmente.

En las últimas décadas la necesidad de ampliar la cobertura llevó a priorizar la cantidad de niños en las escuelas en desmedro de la calidad del servicio. La escuela se direccionó hacia el asistencialismo y la contención volviéndose una organización de corte más social que pedagógico. La escuela como institución se ha hecho cargo de tantas funciones que desatendió su especificidad que es enseñar.

En un recorrido por la literatura nacional las autoras del presente trabajo han podido constatar que hay muy pocos estudios en relación al logro de buenos aprendizajes en estudiantes de enseñanza primaria como consecuencia de la instalación de formatos escolares innovadores. Asimismo, y desde un nivel empírico, se ha podido observar que los docentes mantienen prácticas tradicionales que poco atraen al alumnado.

La Administración Nacional de Educación Pública, a través de comunicados oficiales, propone la implementación de formatos alternativos y sugiere extensión horaria, núcleos educativos integrados, diversificación curricular y escuelas proyectivas. De estos formatos alternativos, que se han visto en algunos centros como proyectos aislados, no ha habido aún una evaluación formal de logros. En los documentos oficiales se relaciona el formato con el tiempo de la jornada escolar, en una extraña relación causal. 


\section{Planteamiento del problema}

En la segunda década del siglo XXI hablar de aprendizaje implica considerar el concepto de aprendizaje en profundidad. El mismo pone el foco en el estudiante y no en el proceso en sí mismo y es definido por Fullan y Langworthy (2014) como "la creación y utilización de nuevos conocimientos en el mundo" (p.8) Aprender en profundidad significa adquirir competencias y saberes que hagan a los alumnos personas creativas, conectadas, aprendiendo toda la vida para que no solo puedan contribuir al bien común sino que sean capaces de crearlo.

Esta concepción trae a escena una nueva pedagogía basada en la asociación de aprendizajes entre estudiantes y docentes y que apela a la motivación intrínseca de ambos por igual.

Cuando se produce fracaso del que aprende, el maestro desempeña un papel trascendente. El fracaso escolar apareció en la agenda pedagógica en las décadas del 60 o del 70 cuando la escuela, en su proceso de democratización, abrió sus puertas a toda la sociedad y aceptó que todos los niños pueden aprender, con más o menos instrumentos cognitivos, pero con posibilidades de hacerlo. En ese momento la escuela debió cambiar la mirada que tenía sobre sí misma como templo del saber y focalizarse en los niños como sujetos de derecho.

A lo largo de sus 34 años de práctica docente una de las dos investigadoras de este trabajo ha podido comprobar que hay niños que transitan por la escuela sin apoderarse de los conocimientos básicos para actuar con criterio y autonomía fuera de ella. Son niños que promueven de grado con los mínimos conocimientos pero siguen rezagados respecto de sus pares. En conocimiento de esto, las autoridades del Consejo de Educación Primaria elaboraron en 2017 un Protocolo de intervención preventiva para aplicar a 4500 alumnos de primer año identificados con dificultades de aprendizaje ya en el nivel inicial, con el fin de acompañar sus trayectorias educativas y evitar el rezagoi.

En el marco de la Encuesta Nacional de Adolescencia y Juventud (2013) realizada por el Instituto Nacional de Estadísticas de Uruguay (INE)ii, casi el 80\% de los jóvenes de entre 15 y 17 años que abandonaron la educación formal señala la falta de interés como una de las razones que los llevaron a abandonar. El aburrimiento puede destacarse como la principal característica que mencionan los estudiantes cuando se les pide que describan la educación.

En el concepto de las presentes autoras, para contrarrestar el fracaso y el rezago escolar debe recuperarse el deseo de aprender por parte de los alumnos. El deseo de aprender elimina la apatía y el aburrimiento, mejora las relaciones interpersonales insatisfactorias, eleva la autoestima, elimina las actitudes negativas hacia la escuela y hacia los pares y mejora el rendimiento escolar.

En la escuela experimental (EE) de esta investigación se observó un marcado descenso de la matrícula en los últimos cinco años así como el porcentaje más alto de repetición del departamento de Paysandú. Se hipotetizó sobre la falta de interés en la propuesta educativa tradicional que ofrece el centro escolar. La investigación describe un formato escolar que motiva el aprendizaje disminuyendo la repetición y el rezago desde la construcción de un ambiente lúdico, creativo, autónomo y participativo instalado por docentes que muestren cambios e innovaciones en sus propuestas de enseñanza. 


\section{Antecedentes}

A efectos de esta publicación se desarrolló el rastreo bibliográfico en dos líneas dominantes: la motivación de los alumnos y el formato Taller. Se focalizó la atención en los antecedentes de campo nacionales e internacionales de los últimos 10 años.

\section{Investigaciones sobre motivación como factor de aprendizaje}

En un recorrido por la literatura sobre esta temática a nivel internacional la primera investigación encontrada en el último decenio es de México efectuada por Valle, Núñez, Cabanach, Rodríguez, González-Pienda y Rosario (2009) sobre los perfiles motivacionales en estudiantes de secundaria, estudio en el que se realiza un análisis diferencial de estrategias cognitivas, autorregulación y rendimiento académico. Con un enfoque más social que académico los investigadores ponen el foco en el mundo de las relaciones interpersonales de los estudiantes.

En España se encuentra la investigación efectuada por González, Del Rincón y Bayot (2010) sobre los enfoques de aprendizaje y rendimiento académico. Estos investigadores distinguen entre enfoques profundos y superficiales. Estos últimos ocurren cuando el estudiante no manifiesta cambios en su estructura cognitiva profunda y solo mantiene un aprendizaje a corto plazo con la única finalidad de aprobar asignaturas. El enfoque profundo, en cambio, implica una reflexión y un relacionamiento de contenidos que conducen a modificaciones cognitivas estructurales. Que el alumno se acerque a uno u otro enfoque dependerá de la manera de enseñar del profesor.

Schunk y Zimmerman (2008) hallaron que muchos estudiantes avanzados en Norteamérica no asumen la responsabilidad del estudio porque no se les han enseñado las habilidades metacognitivas necesarias para obtener logros académicos asertivos. Zimmerman es pionero del aprendizaje autorregulado y demostró que la autorregulación se puede enseñar y aprender para aumentar la motivación y el rendimiento de todos los estudiantes.

Yapur (2016) efectuó un estudio de caso sobre la motivación en el uso de recursos TIC aplicado a estudiantes universitarios argentinos. Los entornos virtuales de aprendizaje (EVA) facilitan la gestión de los procesos de aprendizaje, ofreciendo herramientas y medios suficientes como para desarrollar un aprendizaje significativo y autónomo.

Llama la atención que todos los estudios encontrados que relacionan el aprendizaje con la motivación están orientados hacia alumnos de secundaria y universidad, habiendo localizado escasas investigaciones en el ámbito de educación primaria.

En el ámbito nacional se hallaron dos estudios. Uno fue el realizado por Valdés, Ramírez y Martín (2009) quienes llevaron adelante una investigación en el área de Química, que aportó conocimiento sobre los procesos implicados en el aprendizaje y que permitió valorar el grado en que influye la disposición de los alumnos hacia el aprendizaje y el mejor rendimiento académico. Este estudio demostró que sujetos motivados adoptan mayor compromiso con su aprendizaje, son más competentes, tienen mayor inspiración, usan estrategias más profundas, manifiestan más interés en las tareas y evidencian confianza en sí mismos. El otro estudio fue realizado por Cuevasanta (2014) sobre la motivación para los aprendizajes en escolares de Montevideo. Los resultados muestran una predominancia del polo extrínseco en los factores motivacionales en los grados escolares estudiados $\left(3 .^{\circ}\right.$ y $\left.6 .^{\circ}\right)$. 


\section{Investigaciones sobre Metodología Taller}

Los estudios más profundos relacionados con la metodología de taller se dieron en las décadas del 80-90. Luego dicha metodología cayó en desuso y dado que la temática no forma parte de ninguna agenda educativa actual las autoras del presente trabajo intentan volver a instalarla. Para ello, en el recorrido conceptual se sigue la línea argumental de Ander-Egg (1999), quien emplea el término taller para hacer referencia a la metodología de carácter total que se aplica en un centro educativo, ya sea horizontal o vertical, y al hacer de los docentes. Según Ander-Egg los roles del maestro dentro del taller serán "sensibilizar, motivar, animar a tomar decisiones, enriquecer los procesos personales de elaboración y construcción de significados, enseñar a razonar, a reflexionar y a opinar" (p.48).

En 2011 un pequeño grupo de investigadores iberoamericanos inició una serie de estudios para definir lineamientos en relación al tema de formatos escolares. En este sentido se encuentran los estudios realizados por los siguientes investigadores: GarcíaRavidá (2012); Martínez-Fernández y García Ravidá (2012); Martínez-Fernández y Vermunt (2015); Vermunt, Bronkhorst y Martínez-Fernández (2013). La mayoría de estos estudios se ubican en el contexto de la educación superior. Más recientemente, las investigaciones de Berdonces (2015), Cladellas Pallarès (2015) y Cortés (2015) se han orientado a la exploración de los patrones de aprendizaje en el ámbito de la educación primaria.

En Colombia, Betancourt, Guevara y Fuentes (2011) indagaron sobre la metodología de taller como estrategia didáctica de formación para un aprendizaje significativo en el ámbito de las TIC teniendo en cuenta sus características y retos. El sociólogo colombiano Aponte Penso (2017) realizó una investigación en el ámbito de la educación superior con el fin de conocer el valor del taller como estrategia metodológica para estimular la investigación. Los hallazgos lo validan como un instrumento donde interactúan estudiantes y docente, teoría y práctica, conocimiento y acción.

Se accedió a una reciente investigación realizada por Vargas (2018) en Perú relacionada con el taller de coaching como instrumento para mostrar la apatía escolar como consecuencia de la falta de una dinámica adecuada. La investigadora encontró un factor común en los métodos de enseñanza de los países con mejores niveles educativos y se trata de la participación del alumno en el desenvolvimiento de la clase así como de las didácticas empleadas.

En nuestro país el debate sobre la necesidad de alterar el formato tradicional no es tan fuerte como para ocasionar cambios estructurales. Se trata, sobre todo, de líneas y sugerencias explicitadas en documentos oficiales, más relacionadas a lo organizativo que a la estructura hegemónica reinante. Stevenazzi (2014) realizó una investigación para indagar y analizar las alteraciones producidas a los formatos escolares desde la construcción de política cotidiana, a partir de la experiencia de una escuela pública de un barrio muy vulnerable de la ciudad de Montevideo (capital del Uruguay). En sus conclusiones Stevenazzi opta por emplear el concepto de alteración antes que el de innovación por entender que no se crea nada nuevo sino que se instala un alter que recupera a otro. 
Martinis y Stevenazzi (2014) presentaron un proyecto de investigación que trata el abordaje del desarrollo del formato escolar moderno en Uruguay. Trabajaron sobre dos escuelas públicas: una del ámbito rural y otra integrante del Programa de Maestros Comunitarios. Como resultado de esta investigación plantean el reposicionamiento del docente como un profesional de la educación, promotor de procesos de aprendizaje no solo para sus alumnos sino también para el medio con el que se trabaja.

\section{Fundamentación teórica}

\section{El paradigma de la complejidad del aprendizaje}

El paradigma que mejor se acomoda a las condiciones de una realidad como la que aquí se analiza es el de la complejidad. El paradigma de la complejidad pretende superar el positivismo, la simplificación y la adquisición de conocimientos fragmentados en disciplinas separadas. Morin (2010) plantea que en la complejidad la idea de igualdad es sustituida por la de equidad: frente al concepto de independencia se reivindica la autonomía que incluye la responsabilidad y el compromiso. La complejidad prefiere un alumno que controle su propio proceso de aprendizaje, confíe en su capacidad de resolver situaciones conflictivas en el devenir diario, pueda pensar por sí mismo, sea capaz de movilizar ideas para buscar una respuesta que no está visible a priori y pueda articular todos los recursos de los que dispone para aprender.

A efectos del presente estudio el objeto de análisis de esta investigación, el Taller, se ha optado por una posición intermedia entre el constructivismo y el criticismo.

\section{Implicaciones didácticas de la complejidad: la evaluación y el rendimiento}

La complejidad no pasa por el método didáctico. Lo que está potencialmente en cuestión es la constitución completa de uno mismo como maestro y como persona. Reconocerse a sí mismo como en construcción y deconstrucción permanentes permite alcanzar el desafío de construir una escuela donde el niño aprenda y se sienta verdaderamente pleno.

La adopción de la pedagogía del siglo XXI exige que los docentes se replanteen qué están enseñando, por qué y cómo.

Hay dos aspectos estrechamente relacionados con la mirada que el docente haga de su realidad áulica: cómo evalúa y qué entiende por rendimiento escolar.

Evaluar supone comprender y conocer el proceso de aprendizaje en el individuo y en el grupo y las dificultades que encuentran ambos. Implica ayudar al otro a reflexionar sobre su propio aprendizaje para confrontarlo con el aprendizaje grupal. Implica, asimismo, la realización de instancias metacognitivas donde se piensa sobre la forma en que se aprendió para ir construyendo un conocimiento situado de los estudiantes y actuar en forma estratégica reestructurando las estrategias de intervención.

\section{Pedagogías emergentes}

Fullan y Langworthy (2014) desarrollan una nueva pedagogía emergente: el aprendizaje en profundidad, como respuesta a la crisis del aburrimiento y la frustración tanto de alumnos como de docentes. Hacer con los conocimientos cosas mediadas por la tecnología da a los estudiantes la experiencia, la confianza en sí mismos y la actitud proactiva para la época actual. 
Coincide con este estudio la relación entre los aprendizajes profundos y la concepción de sí mismos que desarrollan los alumnos. La confianza en sí mismo que pueda construir cada alumno aumentará su motivación y le dará herramientas para superar sus dificultades. Un factor de interesante conceptualización es el autoconcepto. Según Garaigordobil y Berrueco (2007) se trata de una construcción cognitiva, única e individual que debe su configuración, también, a las experiencias vividas en sus diferentes contextos. El autoconcepto académico incluye la creencia que desarrollan los alumnos de confiar en su capacidad de poder cumplir con las exigencias del centro en el que estudian, la constancia, la capacidad de superar los fracasos o de tener iniciativa. El autoconcepto es primordial en los primeros años de vida, durante la niñez, ya que la personalidad se configura según las creencias que el entorno -los otros- construyen de cada uno.

Estrechamente relacionada con la motivación de los estudiantes -y desde una mirada psicopedagógica- se encuentra la actitud frente al aprendizaje: las ganas o no de aprender que pueden favorecer u obstaculizar cualquier proceso de enseñanza. Según la actitud de los alumnos se podrá generar o no una instancia de producción de saberes y de transformación de la realidad. Las actitudes son entendidas como estructuras de pensamiento que se expresan y se reflejan a través del lenguaje corporal o de acciones realizadas por el sujeto pensante $y$, por tanto, pueden adquirir diferentes formas ante una situación dada. Un alumno, entonces, puede hallarse ante dos caminos: una actitud positiva o una actitud negativa frente al aprendizaje. Las positivas son actitudes abiertas al diálogo, al cambio, a la renovación, al acercamiento a objetos nuevos y desconocidos. Las actitudes negativas siempre son rígidas, cerradas, resistentes al cambio y generadoras de problemas e inconvenientes.

\section{Formato escolar: El Taller}

Terigi y Perazza (2006) conceptualizan el formato escolar desde los elementos que lo integran como los "tiempos, ritmos, espacios, lugares, modalidades, formas y normas del estar, del saber y del participar" (p.6). El formato escolar tradicional está interpelado por las necesidades educativas del mundo actual. Hablar de formato tradicional es hacer referencia a una modalidad graduada de escuela, que evidencia ciertas marcas tales como la organización de los niños por edad para cada grado, diferenciación de asignaturas, graduación de tiempos y espacios, grupos a cargo de un docente, el aula como unidad espacial y el año escolar como unidad temporal, entre otros. La escuela homogénea tradicional no alcanza hoy para cumplir los fines de la educación. Las prácticas tradicionales se ordenaron en torno a un pasado revestido de autoridad que ya no da respuestas a las necesidades educativas. El gran desafío está en encontrar nuevos formatos institucionales y respuestas pedagógicas más dúctiles que permitan lograr mejores resultados educativos.

Cambiar el formato implica alterar las reglas de organización escolar, las relaciones de poder y el sentido de la institucionalización para producir subjetividades diferentes a las que se producen actualmente. Implica también incluir la noción de circulación del conocimiento. Entran en juego la autonomía profesional, la participación, la construcción y la necesidad de deconstrucción para avanzar.

La organización de un taller es una configuración didáctica que favorece la construcción de un conocimiento procedimental que se construye con la acción. Este tipo de organización supone intervenciones docentes asociadas a metodologías heurísticas que contribuyen a la resolución de problemas a través de la acción. 
El taller constituye un lugar de aprendizaje compartido en el que todos sus participantes construyen socialmente conocimientos y valores y desarrollan habilidades y actitudes a partir de sus propias experiencias. Dentro de este espacio, sin embargo, se diferencian los roles de los educandos y de los educadores pero ambos actúan para el logro de la mejora de la práctica del día a día. El aprendizaje se evidencia en el diálogo constructivo que se logra en el aula. Los procesos de enseñanza y aprendizaje no pueden concebirse para el educando sino con él.

\section{Diseño y metodología}

Se desarrolla una metodología mixta que integra lo cuantitativo y lo cualitativo en un solo estudio. Se trata de un diseño de investigación flexible, que sigue lineamientos orientadores, sin reglas, lo que permite la revisión constante de la producción del conocimiento y la posibilidad de realizar los ajustes necesarios en cuanto a procedimientos, estrategias o técnicas a utilizar en cada caso concreto.

A estos fines se ha implementado un estudio de alcance exploratorio, descriptivo y correlacional en el cual se recolectaron datos a varios niveles, de manera simultánea o en diferentes secuencias. En ocasiones se combinaron los datos cuantitativos y cualitativos para arribar a nuevas variables y temas para futuras pruebas o exploraciones (Hernández Sampieri, Fernández Collado y Batista Lucio, 2010).

Se optó por un diseño cuasi-experimental con grupo control y sin asignación aleatoria. En ambos grupos se aplicó un pre y un postest en los que se observó si el formato taller fue capaz de mejorar el rendimiento general de los alumnos en el aspecto académico a lo largo del ciclo escolar (marzo a diciembre) y si se manifestaban mayores indicios de motivación en las tareas.

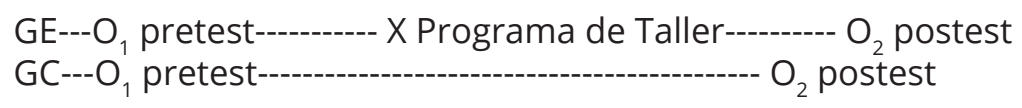

Los instrumentos utilizados se distinguen en función de los estamentos de la muestra: - A los alumnos, como pre y postest, se administraron dos instrumentos estandarizados en aplicación colectiva:

1) Test de diagnóstico integral de estudio (Pérez Avellaneda, Rodríguez Corps, Cabezas Fernández y Polo Mingo, 2002);

2) Inventario de estilos de aprendizaje (ILS), versión española (Vermunt y Verloop, 2000), posterior adaptación al nivel primario latinoamericano (Villar, 2013) y readaptación a la realidad uruguaya por medio de la validación por parte de expertos uruguayos en el año 2017.

- A los docentes:

1) Cuestionario de dilemas sobre la enseñanza y el aprendizaje de Pozo et al. (2006) validado por Vilanova, Mateos-Sanz y García (2011).

2) Análisis de contenido de las planificaciones áulicas y resultados de pruebas estandarizadas elaboradas por el Sistema de Evaluación de Aprendizajes (SEA).

Se trabajó sobre una población de 172 alumnos de $4 .^{\circ}$ a $6 .^{\circ}$ grado, en una franja etaria de entre 10 y 14 años en dos escuelas primarias de Paysandú (Uruguay).

También participaron del estudio 19 docentes entre los que se cuentan maestros de aula de $4 .^{\circ}, 5^{\circ}$ y $6 .^{\circ}$ año, profesores talleristas y directores. 


\section{Resultados}

Los instrumentos utilizados se procesaron mediante análisis factorial, descriptivo, explicativo bivariado y específico para cada test.

Para la información recogida en los cuestionarios se empleó el programa IBM ${ }^{\circledR}$ SPSS $®$ versión 25.0 mediante el cual se realizó el estudio proporcional y comparativo de las respuestas categorizadas de cada ítem en cada test.

A continuación se muestran los gráficos comparativos entre los dos centros educativos, la Escuela Experimental (EE) y la Escuela Control (EC) en relación a uno de los instrumentos empleados -el DIE I- ya que el otro -ILS- corrobora lo hallado.

Tabla 1. Valores descriptivos de los factores que componen el constructo DIE.

\begin{tabular}{|l|c|c|c|c|c|c|c|c|}
\cline { 2 - 8 } \multicolumn{1}{c|}{} & \multicolumn{4}{|c|}{ Primera instancia } & \multicolumn{3}{c|}{ Segunda instancia } \\
\hline Estadísticos descriptivos & $\begin{array}{c}\text { Ptje. } \\
\text { Mín. }\end{array}$ & $\begin{array}{c}\text { Ptje. } \\
\text { Máx. }\end{array}$ & Media & D.E.* & $\begin{array}{c}\text { Ptje. } \\
\text { Mín. }\end{array}$ & $\begin{array}{c}\text { Ptje. } \\
\text { Máx. }\end{array}$ & Media & D.E.* \\
\hline Actitud y estrategias de apoyo & 4 & 9,33 & 6,6257 & 1,22265 & 3,00 & 9,67 & 7,219 & 1,429 \\
A u to c o n c p to y e st ra te g i a s & 2 & 9 & 5,9678 & 1,42941 & 2,67 & 10,00 & 7,970 & 1,832 \\
complementarias & & & & & & & \\
Actitud y estrategias complementarias & 2,33 & 10 & 5,3509 & 1,43069 & 1,67 & 9,67 & 6,873 & 1,854 \\
Autoconcepto y estrategias de apoyo & 1,33 & 9,67 & 5,5263 & 1,52778 & 1,33 & 9,33 & 6,210 & 1,747 \\
Estrategias de apoyo & 3,17 & 9 & 6,076 & 1,12125 & 3,33 & 8,67 & 6,714 & 1,310 \\
Estrategias complementarias & 2,67 & 9,5 & 5,6594 & 1,22723 & 3,50 & 9,67 & 7,421 & 1,700 \\
Actitud & 3,17 & 9,5 & 5,9883 & 1,12313 & 2,83 & 9,00 & 7,046 & 1,449 \\
Autoconcepto & 2,83 & 8,67 & 5,7471 & 1,20965 & 2,83 & 9,33 & 7,090 & 1,494 \\
Aptitud & 3,25 & 8,83 & 5,8677 & 1,02936 & 3,42 & 9,00 & 7,068 & 1,380 \\
\hline
\end{tabular}

Fuente: Elaboración propia.

Puede observarse que de la totalidad de los casos analizados, las medias en la segunda instancia superan a las de la primera y que los rangos en la primera instancia están más concentrados que en la segunda teniendo en cuenta que se trabajó con una escala de 1 a 10. Esto permitió homogeneizar el análisis de factores. 


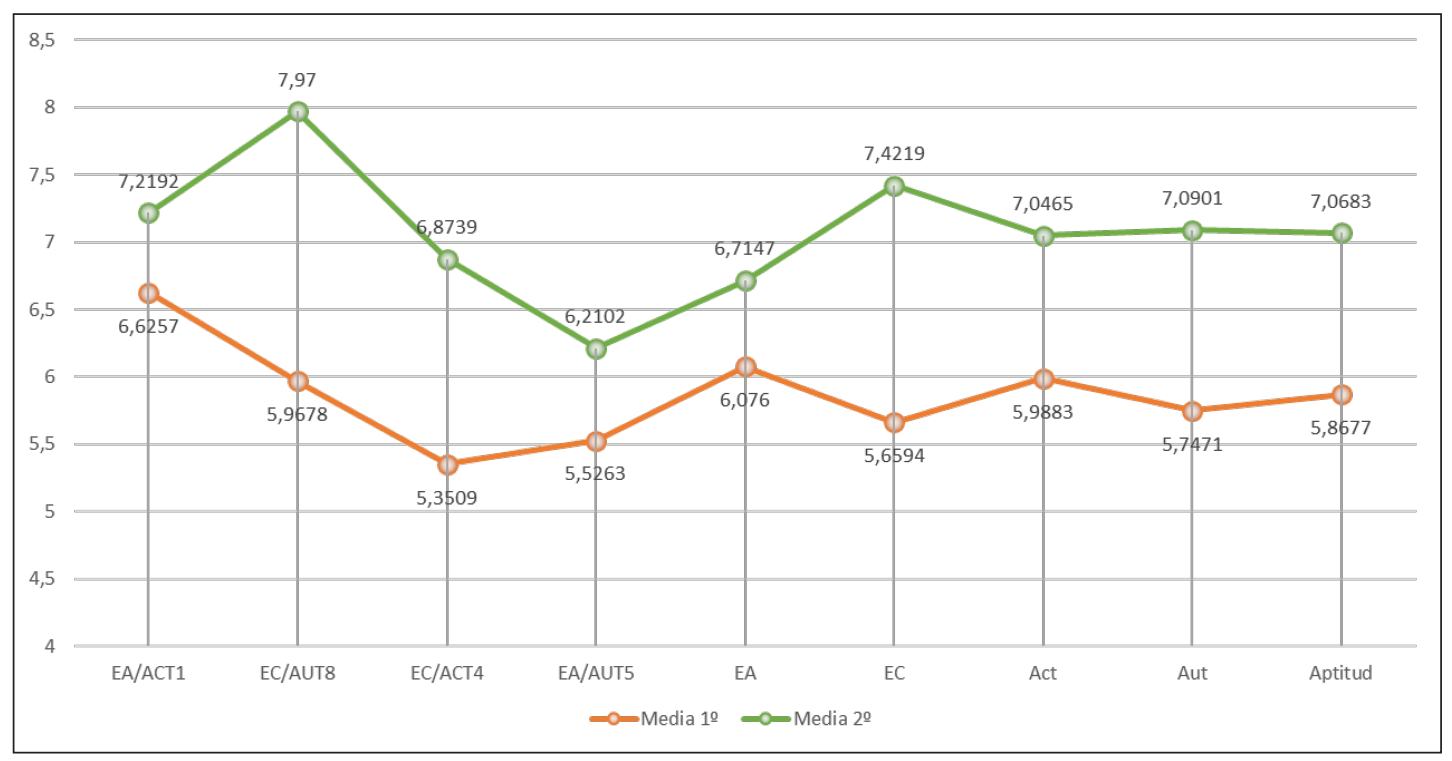

Gráfico 1. Distribución de Medias. DIE 1.

Fuente: Elaboración propia.

Como puede observarse, las medias de la segunda instancia -en color verde- son superiores a las de la primera. Ello significa que todos los factores considerados - actitud y estrategias de apoyo, autoconcepto y estrategias complementarias, actitud y estrategias complementarias, autoconcepto y estrategias de apoyo, estrategias complementarias, actitud, autoconcepto y aptitud- se vieron fortalecidos a lo largo del curso.

Considerando la limitada extensión de la publicación se comunican los resultados de 6..$^{\circ}$ ño en forma comparada entre las dos escuelas según puntuaciones directas y percentiles.

Tabla 2: Puntuaciones y percentiles en relación con los baremos estándar para $6 .^{\circ}$ grado en ambas instancias de relevamiento.

\begin{tabular}{|c|c|c|c|c|c|c|c|c|c|c|}
\hline & \multicolumn{4}{|c|}{ Primera instancia } & \multicolumn{4}{|c|}{ Segunda instancia } & \multirow{2}{*}{\multicolumn{2}{|c|}{$\begin{array}{c}\text { Baremo } \\
\text { Media }\end{array}$}} \\
\hline & \multicolumn{2}{|c|}{$6 .^{\circ}$ control } & \multicolumn{2}{|c|}{$6^{\circ}$ experimental } & \multicolumn{2}{|c|}{$6 .^{\circ}$ control } & \multicolumn{2}{|c|}{$60^{\circ}$ experimental } & & \\
\hline & Punt. & Percent. & Punt. & Percent. & Punt. & Percent. & Punt. & Percent. & Punt. & Percent. \\
\hline EAACT & 19,33 & 25 & 19,81 & 30 & 18,06 & 15 & 24,68 & 85 & 21,56 & 50 \\
\hline ECAUT & 18,17 & 25 & 17,53 & 25 & 16,72 & 20 & 27,68 & 95 & 20,6 & 50 \\
\hline ECACT & 12,83 & 1 & 16,23 & 15 & 12,06 & 1 & 24,44 & 85 & 20,35 & 50 \\
\hline EAAUT & 14,00 & 20 & 16,40 & 30 & 12,61 & 15 & 20,41 & 70 & 18,04 & 50 \\
\hline EA & 33,33 & 15 & 36,21 & 30 & 30,67 & 30 & 45,10 & 75 & 39,61 & 50 \\
\hline EC & 31,00 & 5 & 33,77 & 15 & 28,78 & 3 & 52,12 & 95 & 40,95 & 50 \\
\hline ACT & 32,17 & 5 & 36,05 & 15 & 30,11 & 3 & 49,12 & 85 & 41,91 & 50 \\
\hline AUT & 32,17 & 15 & 33,93 & 25 & 29,33 & 10 & 48,10 & 85 & 38,64 & 50 \\
\hline APT & 64,33 & 5 & 69,98 & 20 & 59,44 & 1 & 97,22 & 90 & 80,55 & 50 \\
\hline
\end{tabular}

Fuente: Elaboración propia. 
En la tabla 2 pueden apreciarse los valores obtenidos por los alumnos de $6 .^{\circ}$ grado en ambas instancias de relevamiento y se pueden comparar con los valores del baremo.

Gráfico 2. Relación de percentiles obtenidos respecto del baremo para $6 .^{\circ}$ grado en ambas instancias de relevamiento.

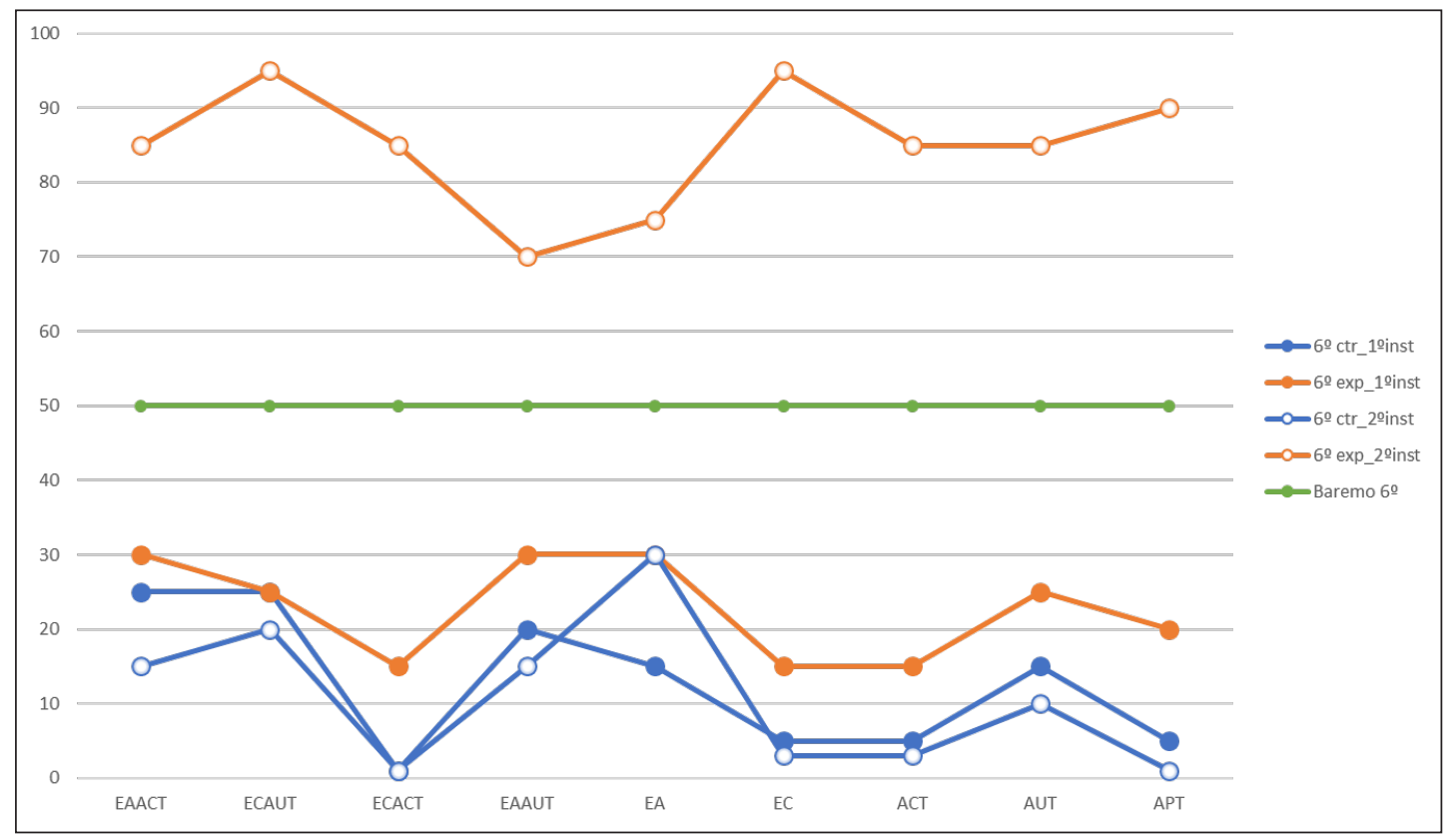

Fuente: Elaboración propia, a partir del análisis efectuado en Microsoft® Excel®. DIE 1

En el gráfico 2 puede observarse que los percentiles obtenidos en la segunda instancia de relevamiento (color naranja con puntos blancos) están por encima de los del baremo. Todos los percentiles obtenidos por el grupo control tanto en la primera instancia como en la segunda se encuentran ubicados por debajo de los resultados del baremo, incluso algunos de los factores del grupo de control disminuyeron en la segunda instancia de relevamiento. En este caso en particular puede apreciarse que los valores del grupo experimental se acrecentaron considerablemente ya que antes de la aplicación los percentiles no llegaban a la media y en la segunda instancia de relevamiento todos los factores la superan.

\section{¿Los alumnos se aburren en clase?}

Según las investigadoras es importante analizar específicamente el ítem 42 del DIE que expresa: "me aburro en las clases", considerando que es de interés saber si los estudiantes se motivan en los talleres o por el contrario se aburren y manifiestan desinterés y desgano. El aburrimiento es un estado emocional de letargo acompañado de una sensación de alargamiento del tiempo. 
Tabla 3. Comparación de respuestas afirmativas al Ítem 42 en las dos instancias de aplicación en las dos escuelas.

\begin{tabular}{|c|c|c|c|c|c|c|c|}
\hline & & \multicolumn{3}{|c|}{ B42 1. instancia } & \multicolumn{3}{|c|}{ B42 2. instancia } \\
\hline & & $\begin{array}{c}\text { Sí 1. }{ }^{\mathrm{a}} \\
\text { instancia }\end{array}$ & $\begin{array}{c}?^{\mathrm{a}} \\
\text { instancia }\end{array}$ & $\begin{array}{c}\text { No } 1 .^{a} \\
\text { instancia }\end{array}$ & $\begin{array}{c}\text { Sí } 2 .^{a} \\
\text { instancia }\end{array}$ & $\begin{array}{c}\text { ? }^{\mathrm{a}} \\
\text { instancia }\end{array}$ & $\begin{array}{c}\text { No } 2 .^{a} \\
\text { instancia }\end{array}$ \\
\hline \multirow{3}{*}{ Escuela No 178} & $4 .^{\circ}$ grado & 13 & 0 & 11 & 14 & 5 & 6 \\
\hline & $5 .^{\circ}$ grado & 9 & 0 & 11 & 8 & 3 & 8 \\
\hline & $6 .^{\circ}$ grado & 9 & 4 & 5 & 13 & 4 & 1 \\
\hline \multirow{3}{*}{ Escuela Nº 201} & 4. ${ }^{\circ}$ grado & 13 & 0 & 17 & 0 & 2 & 30 \\
\hline & $5 .^{\circ}$ grado & 11 & 4 & 18 & 1 & 1 & 31 \\
\hline & $6 .^{\circ}$ grado & 22 & 10 & 11 & 1 & 6 & 34 \\
\hline
\end{tabular}

Fuente: Elaboración propia.

Puede observarse claramente que en la escuela en la que se ha instalado el Taller disminuyó el aburrimiento en clase. En $6 .^{\circ}$ año, concretamente, a comienzo de año indicaron sí aburrirse 22 niños y al finalizar el año solo uno mantuvo su respuesta. No ocurrió lo mismo en la EC: en $6 .^{\circ}$ año nueve alumnos indicaron aburrirse en la primera instancia y fueron 13 los que respondieron afirmativamente en la segunda. El formato tradicional ya no entusiasma a los estudiantes, por el contrario, los desmotiva.

Gráfico 3. Comparativo del ítem 42 en la respuesta Sí.

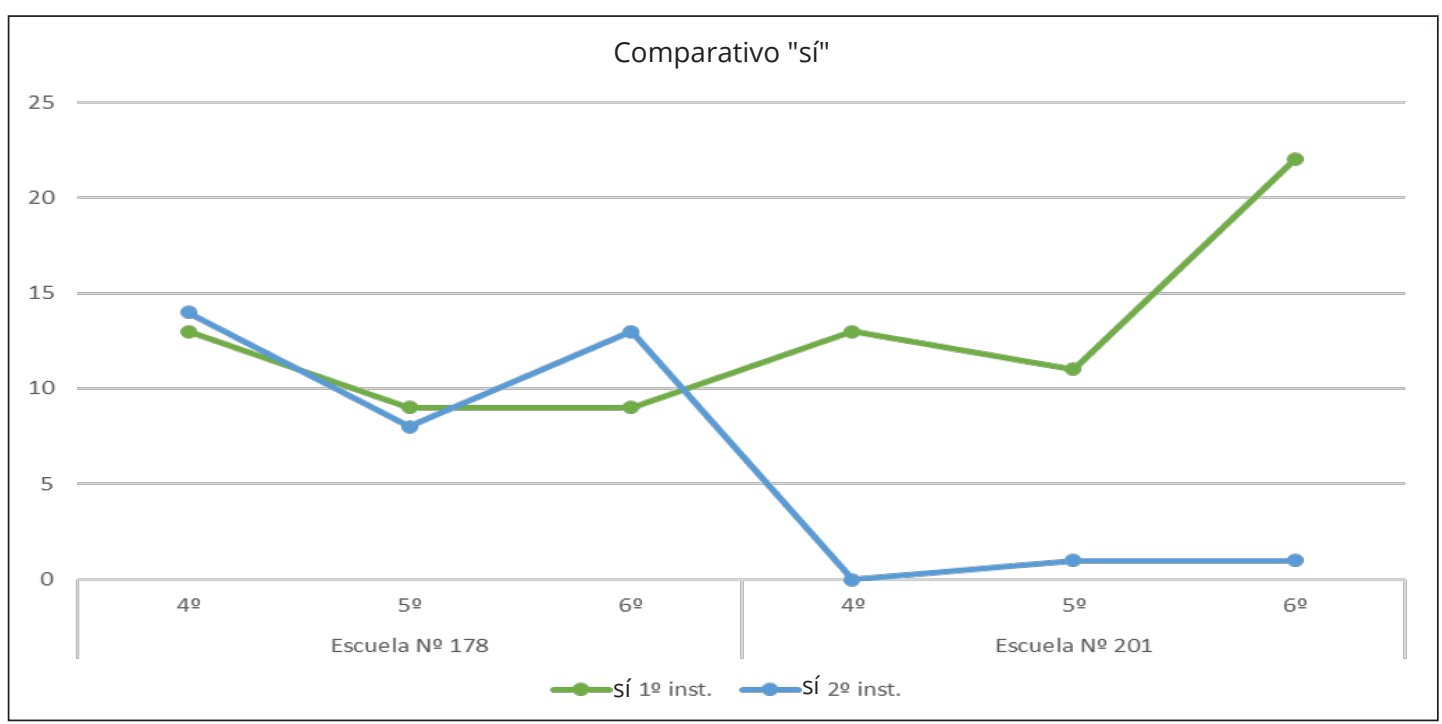

Fuente: Elaboración propia.

En el gráfico puede observarse lo que ocurre con el aburrimiento según los grados y las escuelas de referencia. Tanto en la primera como en la segunda instancia, en la escuela control los alumnos manifestaron aburrirse en clase casi en la misma proporción. En cambio, en la escuela experimental hay un margen pronunciado. Los estudiantes afirmaron aburrirse en clase en la primera instancia pero descendieron drásticamente sus respuestas afirmativas en la segunda aplicación en la escuela experimental. Esto se 
atribuye al formato establecido, con mayor flexibilidad y adaptación a las necesidades de los alumnos, que implica mayor involucramiento y menor posibilidad de aburrirse durante las actividades áulicas. Completan los resultados obtenidos por el DIE los datos recogidos con el instrumento ILS.

Tabla 4. Valores descriptivos de los factores que componen el constructo ILS para ambos grupos de ambas instancias.

\begin{tabular}{|c|c|c|c|c|c|c|c|c|c|c|c|}
\hline \multirow{3}{*}{\multicolumn{2}{|c|}{ Estadísticos descriptivos }} & \multirow{2}{*}{\multicolumn{5}{|c|}{ Grupo Control }} & \multirow{2}{*}{\multicolumn{5}{|c|}{ Grupo Experimental }} \\
\hline & & & & & & & & & & & \\
\hline & & Casos & $\begin{array}{l}\text { Ptje. } \\
\text { Mín. }\end{array}$ & $\begin{array}{l}\text { Ptje. } \\
\text { Máx. }\end{array}$ & Media & D.E.* & Casos & $\begin{array}{l}\text { Ptje. } \\
\text { Mín. }\end{array}$ & $\begin{array}{l}\text { Ptje. } \\
\text { Máx. }\end{array}$ & Media & D.E.* \\
\hline \multirow{3}{*}{$\begin{array}{c}1 . a \\
\text { instancia }\end{array}$} & Autorregulación & 75 & 1,00 & 2,40 & 1,575 & ,3255 & 97 & ,90 & 2,60 & 1,639 & ,3842 \\
\hline & Regulación Externa & 75 & 1,09 & 2,82 & 1,690 & 3796 & 97 & 1,00 & 2,91 & 1,703 & ,4562 \\
\hline & $\begin{array}{l}\text { Carencia de } \\
\text { Regulación }\end{array}$ & 75 & 1,00 & 3,00 & 1,820 & ,4505 & 97 & 1,00 & 2,80 & 1,853 & ,3920 \\
\hline \multirow{3}{*}{$\begin{array}{c}2 . a \\
\text { instancia }\end{array}$} & Autorregulación & 74 & 4 & 6 & 4,889 & 0,383 & 97 & 7,4 & 9,4 & 8,414 & 0,437 \\
\hline & Regulación Externa & 74 & 4 & 6 & 4,975 & 0,383 & 97 & 7,45 & 10 & 8,384 & 0,442 \\
\hline & $\begin{array}{l}\text { Carencia de } \\
\text { Regulación }\end{array}$ & 74 & 4 & 7,2 & 5,502 & 0,823 & 97 & 5,6 & 9,6 & 7,851 & 0,855 \\
\hline
\end{tabular}

Fuente: Elaboración propia.

Gráfico 4. Análisis descriptivo por cada grupo (experimental y control) en ambas instancias.

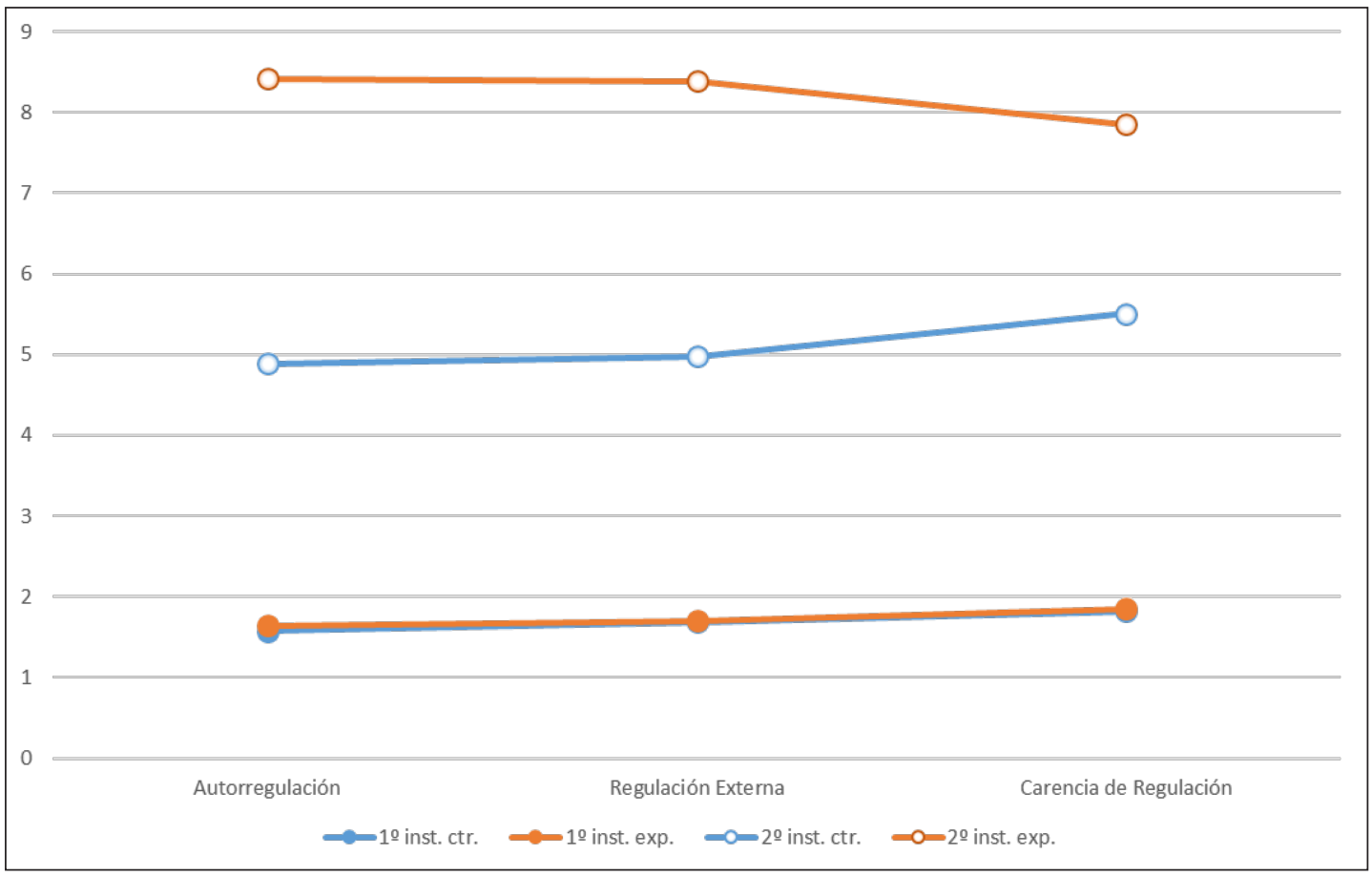

Fuente: Elaboración propia. 
En este gráfico se puede apreciar cómo se distribuyen las medias de ambos grupos en las dos instancias de relevamiento. El dato que sobresale es el de las medias del grupo experimental durante la segunda instancia de relevamiento (color naranja con puntos blancos) debido al incremento de valores respecto de la primera instancia de relevamiento (color naranja con puntos naranja).

Si bien el grupo control (líneas azules) también muestra un incremento significativo respecto a ambas instancias de relevamiento, el incremento en el grupo experimental de la segunda instancia (color naranja con puntos blancos) es muy superior al del grupo control (color azul con puntos blancos).

\section{Resultados de aprendizaje}

Para conocer la incidencia del nuevo formato en los aprendizajes se analizaron los logros en lectura según información recogida en pruebas formativas elaboradas por el Sistema de Evaluación de Aprendizajes (SEA) y desarrolladas por el Departamento de Evaluación de la División Investigación, Evaluación y Estadística (DIEE) de la Dirección Sectorial de Planificación Educativa de la Administración Nacional de Educación. Se trata de pruebas en línea, una modalidad de evaluación que ha sido posible gracias a la infraestructura tecnológica instalada por el Plan Ceibal en los centros educativos. Además de posibilitar la cobertura nacional estas pruebas permiten obtener resultados al instante sobre algunos aspectos del aprendizaje para reflexionar e intervenir sobre la enseñanza. Las competencias que se evalúan son: construcción de significado en sus dos procesos, lectura literal e inferencial y reflexiones sobre la lengua.

Si se comparan los resultados obtenidos por alumnos de $6 .^{\circ}$ año en ambas escuelas (E.E y E.C) puede observarse que en todos los contenidos hay primacía de la escuela en la que se ha implementado un nuevo formato. 
Tabla 5. Comparación de resultados en prueba formativa de lectura entre ambas escuelas en $6 .^{\circ}$ año.

\begin{tabular}{|c|c|c|c|}
\hline & $\begin{array}{l}\text { Grupo } \\
\text { Control }\end{array}$ & $\begin{array}{c}\text { Grupo } \\
\text { Experimental }\end{array}$ & Comparativo \\
\hline Lectura inferencial & 32 & 26 & -6 \\
\hline Lectura literal & 27 & 64 & +37 \\
\hline Lectura literal & 36 & 44 & +8 \\
\hline Lectura literal & 67 & 72 & +5 \\
\hline Lectura inferencial & 48 & 64 & +16 \\
\hline Puntuación & 57 & 72 & +15 \\
\hline Voces en el texto & 24 & 28 & +4 \\
\hline Lectura inferencial & 0 & 10 & +10 \\
\hline Lectura literal & 60 & 82 & +22 \\
\hline Lectura inferencial & 30 & 33 & +3 \\
\hline Interpretación de recursos gráficos & 80 & 26 & 54 \\
\hline Lectura literal & 40 & 41 & +1 \\
\hline Lectura literal & 60 & 67 & +7 \\
\hline Lectura literal & 10 & 18 & +8 \\
\hline Lectura literal & 30 & 49 & +19 \\
\hline Lectura literal & 70 & 69 & 1 \\
\hline Lectura inferencial & 35 & 59 & +24 \\
\hline Lectura literal & 0 & 0 & 0 \\
\hline Función de elementos paratextuales & 45 & 49 & +4 \\
\hline Función referencial del pronombre & 15 & 41 & +26 \\
\hline
\end{tabular}

Fuente: Elaboración propia a partir del análisis efectuado con el SPSS. Rendimiento Académico.

Analizando estos resultados se observa una clara superioridad de logros en la EE en la mayoría de los ítems valorados, con excepción de la interpretación de recursos gráficos que da valores por debajo de la EC.

Los gráficos siguientes lo explicitan con mayor claridad. 


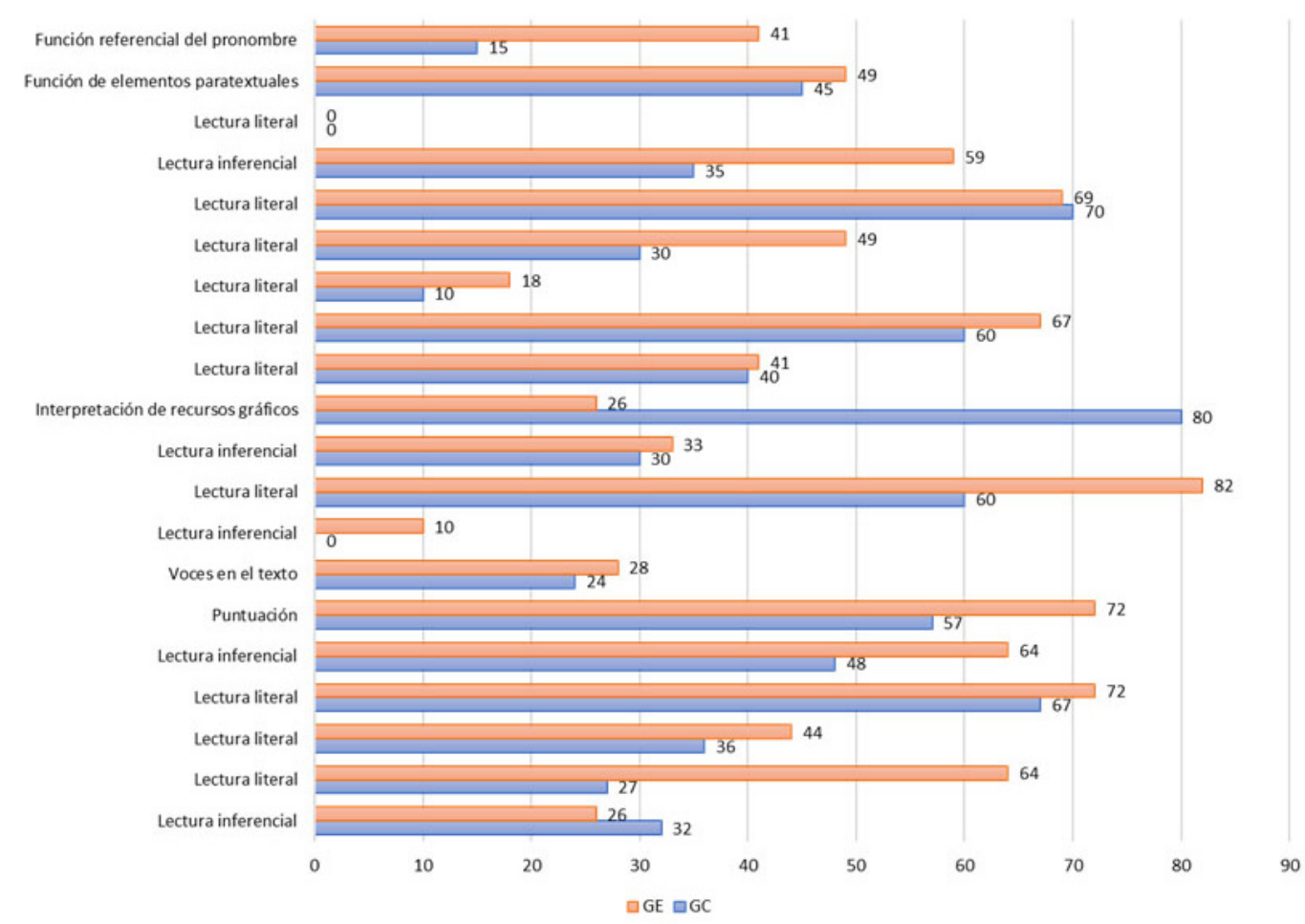

\section{Conclusiones}

Luego de un recorrido por los cambios observados en la escuela experimental en relación a la escuela control y en función de las hipótesis planteadas al comienzo del estudio, es posible realizar un análisis de mayor profundidad.

* Primera hipótesis: el formato escolar Taller motiva a los alumnos en la realización de sus tareas diarias.

En el análisis de resultados obtenidos por medio del Diagnóstico Integral de Estudio (DIE) se encontró una mejora sustantiva de todas las variables: actitud y estrategias de apoyo, autoconcepto y estrategias complementarias, actitud y estrategias complementarias, autoconcepto y estrategias de apoyo, estrategias de apoyo, estrategias complementarias, actitud, autoconcepto y aptitud, en los grupos de la Escuela Experimental (EE) en relación con los grupos de la Escuela Control (EC).

Fue posible comprobar que estar motivados conduce a los estudiantes a poner más esfuerzo en la tarea, genera más iniciativas y mejora el involucramiento cognitivo afectando en forma directa los aprendizajes. Las variables medidas -tales como actitud, autoconcepto y aptitud, estrategias de apoyo y estrategias complementariasse acrecientan en el postest en la EE. En cambio, en la EC parece haber existido un estancamiento ya que ninguno de los factores logra superar la media ni en la primera ni en la segunda instancia de aplicación.

Para profundizar en la información sobre la mejora en las condiciones de predisposición de los alumnos para el estudio se complementó con datos del Inventario de Estilos de Aprendizaje (ILS), instrumento que corroboró un cambio significativo de los tres aspectos medidos: autorregulación, regulación externa y carencia de regulación. 
Por una parte, en el punto de partida se vio una homogeneidad entre ambos grupos pero en la segunda instancia el incremento en el grupo experimental es superior al grupo control en lo que refiere a autorregulación y regulación externa. Por otra parte disminuyó el número de alumnos que carecen de regulación en la Escuela Experimental y, en cambio, aumentó en la Escuela Control. Por tanto, las autoras consideran que contar con estrategias de autorregulación prepara mejor a los estudiantes para enfrentar las exigencias de una sociedad más competitiva y demandante.

En la EE los alumnos se aburren menos y se sienten con mayor motivación frente a las actividades que propone el docente. Las autoras atribuyen este cambio de estado emocional al nuevo formato y según los resultados consideran que el formato tradicional puede incluso obstaculizar el normal proceso de aprendizaje. Un dato interesante que arrojó el DIE sobre la EC es que en la segunda instancia de aplicación (postest) las variables actitud, autoconcepto y aptitud decrecieron respecto de la primera instancia de aplicación (pretest). Esto significa que los valores de las medias disminuyeron con el tiempo de manera casi proporcional para todos los factores de análisis en el grupo control con una enseñanza tradicional. Ello explicaría la falta de motivación y de interés de los estudiantes que los predispone con una actitud negativa hacia la propuesta educativa de la escuela con formato tradicional.

* Segunda hipótesis: el formato escolar Taller mejora la actitud de los estudiantes hacia los aprendizajes.

También el Diagnóstico Integral de Estudio (DIE) aportó información sobre la actitud de los estudiantes frente al estudio. Se observó una correlación positiva entre el nuevo formato y las variables autoconcepto y actitud. En la segunda instancia de aplicación (postest), las medias en la EC quedaron significativamente por debajo de las medias en la EE. Esto indica que los factores involucrados en el aprendizaje tales como actitud, aptitud y autoconcepto mejoran al aplicar el nuevo formato pedagógico.

De todas las variables analizadas se visualiza que las estrategias que hacen a la calidad del aprendizaje que reciben los alumnos son las complementarias: los estudiantes tienen un sistema de estudio personal, realizan anotaciones en el margen, utilizan técnicas de síntesis, se autoanalizan en función de los resultados de aprendizaje y tienen claro qué hacer para estudiar asertivamente. En cuanto a las tareas para el hogar organizan sus horarios, comprueban si han cumplido con lo solicitado antes de dejar de estudiar, estudian todos los días y no se conforman con estudiar lo imprescindible.

* Tercera hipótesis: el formato escolar Taller provoca cambios en las prácticas de enseñanza de los docentes.

El cuestionario de Dilemas (Vilanova et al., 2011) aplicado permitió visibilizar las teorías que dominan el accionar docente en la EE y subyacen a sus concepciones profesionales. Existe una marcada predominancia de conceptualizaciones basadas en las teorías constructiva e interpretativa. Entre ambas conforman el $88 \%$ del total de las respuestas. En consecuencia, la Teoría Directa solo cuenta con un 12\% del total de las respuestas. Esto significa que más de las tres cuartas partes de los docentes entienden que la enseñanza debe apoyarse en metodologías activas, que los estudiantes deben participar vivamente en las tareas que se les proponen y que el profesor desempeña un papel esencial en la creación de escenarios educativos significativos. 
La teoría constructivista predomina en las definiciones de aprender y de qué se aprende. Se entiende que aprender es cuando el objeto de estudio es factible de ser transformado por el estudiante en su proceso reflexivo. Por su parte, se aprende a partir de ideas previas sobre las que cada estudiante podrá pensar, así como contrastarlas con los modelos científicos y construir a partir de ellas su nuevo conocimiento.

La teoría interpretativa tiene predominancia muy acentuada en relación con el cómo se aprende. Se aprende procurando que los alumnos desarrollen estrategias que les permitan asignarle significado a lo que aprenden, favoreciendo situaciones en las que puedan desarrollar capacidades para realizar comparaciones, argumentar y desarrollar un pensamiento crítico respecto del tema a aprender y estudiar con materiales bibliográficos a la vista, siempre y cuando se acompañe con alguna otra tarea que permita comprobar que el alumno conoce la información solicitada.

Para complementar los datos recogidos por el instrumento Dilemas se apeló al estudio de documentos elaborados por docentes: concretamente sus planificaciones tanto a largo como a corto plazo. Se seleccionaron los siguientes aspectos a observar, en el entendido de que son aspectos que hacen a la buena enseñanza: organización del currículo, organización de su enseñanza, objetivos de su enseñanza, proceso de evaluación y planificación de la evaluación.

En los cinco aspectos los valores medios en la Escuela Experimental (EE) fueron significativamente superiores a los valores de la Escuela Control (EC). Esto lleva a concluir que un formato diferente al tradicional, en este caso el Taller, incide favorablemente en la forma en que los docentes piensan su enseñanza.

En la documentación docente pudo constatarse que los maestros implican a los estudiantes con metodologías activas que exigen participación e involucramiento. Los cuestionan, hacen que elaboren sus propias preguntas y que empleen su propio reservorio lingüístico para explicar situaciones.

\section{Consideraciones finales}

El formato taller se presenta como una experiencia que permite pensar y reflexionar el dispositivo escolar tradicional desde una opción diferente.

El nuevo formato muestra adaptarse a las necesidades de una sociedad compleja ya que no se observan tiempos rígidos ni rutinarios sino que hay una construcción de conocimientos desde la interacción, ya sea entre los propios alumnos o entre estos y los docentes. Las estrategias de trabajo colaborativo, la comunicación, el pensamiento creativo y la resolución de problemas se ven potenciados. De esta manera se halló que el taller es una buena alternativa para combatir el aburrimiento en las aulas, disminuir la repetición y combatir el rezago escolar. 


\section{Referencias bibliográficas}

Ander-Egg, E. (1999). El taller: una alternativa de renovación pedagógica. Buenos Aires: Editorial Magisterio del Río de La Plata.

Aponte Penso, R. (2017). El taller como estrategia metodológica para estimular la investigación en el proceso de enseñanza-aprendizaje en la educación superior. Revista Boletín Redipe, 4(10), 49-55. https://revista.redipe.org/index.php/1/article/view/328

Betancourt Jaimes, R., Guevara Murillo, L. N. \& Fuentes Ramírez, E. M. (2011). El taller como estrategia didáctica, sus fases y componentes para el desarrollo de un proceso de cualificación en el uso de tecnologías de la información y la comunicación (TIC) con docentes de lenguas extranjeras: Caracterización y retos. https://ciencia.lasalle.edu.co/lic_lenguas/305/

Berdonces Ballesteros, A. (2015). Relación entre los patrones de aprendizaje de los maestros y la implicación familiar con el patrón de aprendizaje de los niños en Educación Primaria. Trabajo de Grado. Universidad Autónoma de Barcelona.

Cladellas Pallarès, J. (2015). Patrones de aprendizaje: la implicación de la familia y el rol de los maestros en el aprendizaje de alumnos de once y doce años en Cataluña. Trabajo de Grado. Universidad Autónoma de Barcelona.

Cortés, E. (2015). Patrones de aprendizaje según la edad: una aproximación con alumnos de Educación Primaria en Cataluña. Trabajo de Grado. Universidad Autónoma de Barcelona.

Cuevasanta, D. (2014). Una aproximación al estudio de la motivación por el aprendizaje en escolares de Montevideo. Trabajo final de grado. Montevideo: Facultad de Psicología. https://www.colibri.udelar.edu.uy/jspui/bitstream/20.500.12008/5278/1/CUEVASANTA. pdf

Fullan, M. y Langworthy, M. (2014). Una rica veta. Cómo las nuevas pedagogías logran el aprendizaje en profundidad. Londres: Pearson. https://www.pearson.com/content/ dam/one-dot-com/one-dot-com/global/Files/about-pearson/innovation/open-ideas/ ARichSeamSpanish.pdf

Garaigordobil, M. y Berrueco, L. (2007). Autoconcepto de niños y niñas de 5 años: relaciones con inteligencia, madurez neuropsicológica, creatividad, altruismo y empatía. Infancia y aprendizaje, 30(4), 551-564. https://doi.org/10.1174/021037007782334337 https://redined.mecd.gob.es/xmlui/bitstream/handle/11162/79210/Autoconcepto. pdf? sequence=1\&isAllowed $=y$

García-Ravidá, L. B. (2012). Patrones de aprendizaje en universitarios latinoamericanos. Dimensión cultural e implicaciones educativas. Tesis doctoral. Universidad Autónoma de Barcelona. https://ddd.uab.cat/pub/tesis/2017/hdl_10803_454839/lbgr1de1.pdf

González, J., Del Rincón, B. y Bayot, A. (2010). Enfoques de aprendizaje y rendimiento académico en educación secundaria. Revista Galego-Portuguesa de Psicoloxía e Educación, 18, (1), 211-226. https://core.ac.uk/download/pdf/61903119.pdf 
Hernández Sampieri, R., Fernández Collado, C. y Baptista Lucio, M. (2010). Metodología de la investigación (5. ${ }^{a}$ ed.) México: McGraw Hill. https://www.esup.edu.pe/descargas/ dep_investigacion/Metodologia\%20de\%20la\%20investigaci\%C3\%B3n\%205ta\%20 Edici\%C3\%B3n.pdf

INJU/MIDES (2015). Informe Tercera Encuesta Nacional de Adolescencia y Juventud, 2013. https://data.miraquetemiro.org/sites/default/files/documentos/informe-tercera-enajfinal.pdf

Martínez-Fernández, J. R. y García-Ravidá, L. B. (2012). Patrones de aprendizaje en estudiantes universitarios del Máster en Educación Secundaria: variables personales y contextuales relacionadas. Revista de currículum y formación del profesorado, 16(1), 165182. https://www.redalyc.org/articulo.oa?id=567/56724377010

Martínez-Fernández, J. R. y Vermunt, J. D. (2015). A cross-cultural analysis of the patterns of learning and academic performance of Spanish and Latin-American undergraduates. Studies in Higher Education, 40(2), 278-295. https://doi.org/10.1080/03075079.2013.823 934, https://www.researchgate.net/publication/256471629_A_cross-cultural_analysis of the_patterns_of_learning_and_academic_performance_of_Spanish_and_Latin-_ American_undergraduates

Martinis, P. y Stevenazzi, F. (2014). Movimientos y alteraciones de la forma escolar en la escuela primaria de Uruguay. Políticas Educativas, Porto Alegre, 7(2), 89-109. http://dedicaciontotal.udelar.edu.uy/adjuntos/produccion/1437_academicas academicaarchivo.pdf

Morin, E. (2010). Introducción al pensamiento complejo. Barcelona: Gedisa.

http://cursoenlineasincostoedgarmorin.org/images/descargables/Morin_Introduccion_ al_pensamiento_complejo.pdf

Pérez Avellaneda, M., Rodríguez Corps, E., Cabezas Fernández, M. y Polo Mingo, A. (2002). Diagnóstico integral del estudio, DIE, (niveles 1, 2 y 3). Madrid: TEA Ediciones.

Pozo, J. I., Scheuer, N., Pérez Echeverría, M. P., Mateos, M., Martín, E. y De la Cruz, M. (2006). Nuevas formas de pensar la enseñanza y el aprendizaje. Las concepciones de profesores y alumnos. Barcelona: Graó.

Schunk, D. H. \& Zimmerman, B. J. (Eds.). (2008). Motivation and self-regulated learning: Theory, research, and applications. Lawrence Erlbaum Associates Publishers.

Stevenazzi, F. (2014). Una lectura sobre la producción de alteraciones a los formatos escolares desde la política cotidiana de la escuela. Revista científica Vozes dos Vales 6 (3). https://www.academia.edu/9075970/Una_lectura_sobre_la_producci\%C3\%B3n_de_ alteraciones_a_los_formatos_escolares_desde_la_pol\%C3\%ADtica_cotidiana_de_la_ escuela

Terigi, F. Y Perazza, R. (2006). Las tensiones del formato escolar en las nuevas configuraciones de la relación familia/comunidad/escuela: una experiencia de educación infantil en la ciudad de Buenos Aires. Journal of Education for International Development 2; 3. http://blogs.unlp.edu.ar/pec/files/2014/11/Terigi-Jardines-comuniitlasTensionesDelFormatoEscolar.pdf 
Valdés, A., Ramírez, C. y Martín, M. (2009). Motivación hacia el estudio de la Química en estudiantes de Bachillerato Tecnológico. Revista Iberoamericana de Educación, 48 (3), 1-11. https://rieoei.org/historico/deloslectores/2361Cuervov2.pdf

Valle, A., Núñez, J., Cabanach R., Rodríguez, S., González-Pienda, J. y Rosario, P. (2009). Perfiles motivacionales en estudiantes de secundaria: análisis diferencial en estrategias cognitivas, estrategias de autorregulación y rendimiento académico. Revista Mexicana de Psicología, 26 (1), 113-124. http://www.redalyc.org/articulo.oa?id=243016317011

Vargas, A. (2018). Taller de coaching como instrumento para mostrar la apatía escolar como consecuencia de la falta de una dinámica adecuada. Tesis de Licenciatura. Perú. Universidad San Ignacio de Loyola. http://repositorio.usil.edu.pe/bitstream/USIL/3148/3/2018 VargasCarri\%C3\%B3n.pdf

Vermunt, J. D., \& Verloop, N. (2000). Dissonance in students' regulation of learning processes. Eur J Psychol Educ 15, 75. https://doi.org/10.1007/BF03173168

Vermunt, J. D., Bronkhorst, L. H. \& Martínez-Fernández, J. R. (2013). The dimensionality in student learning patterns in different cultures. In Gijbels, D. (Ed.), Donche, V. (Ed.), Richardson, J. (Ed.), Vermunt, J. (Ed.). (2014). Learning Patterns in Higher Education. London: Routledge. https://doi.org/10.4324/9781315885438

Vilanova, S., Mateos-Sanz, M. M. \& García, M. B. (2011). Las concepciones sobre la enseñanza y el aprendizaje en docentes universitarios de ciencias. Revista Iberoamericana de Educación Superior, II(3), 53-75.

https://www.redalyc.org/articulo.oa?id=2991/299124244003

Villar, L. (2013).Perfiles de aprendizaje y rendimiento académico en niñas de educación primaria. ¿Orientadas desde la autorregulación, la regulación externa o la carencia de regulación? Tesis de maestría. Venezuela: Universidad Católica Andrés Bello. http:// biblioteca2.ucab.edu.ve/anexos/biblioteca/marc/texto/AAS7451.pdf

Yapur, J. (2016). Nuevos formatos escolares para la escolarización secundaria: un estudio del programa Inclusión y Terminalidad de la escuela secundaria para jóvenes de 14 a 17 años en la provincia de Córdoba. Revista digital Educación, Formación e investigación, 2, (3). http://ppct.caicyt.gov.ar/index.php/efi/article/view/8217/8082

\section{(cc) BY}

Este artículo está sujeto a una licencia internacional Creative Commons Attribution 4.0. 
* Universidad Internacional Iberoamericana

** Universidad Nacional de Cuyo, Argentina

${ }^{1}$ Doctora (Cand.) en Educación, Universidad Internacional Iberoamericana (México). Master en Educación, Universidad ORT Uruguay. Postgrado en Gestión de Instituciones Educativas, Universidad de la República (Uruguay). Maestra de Educación Primaria, Instituto de Formación Docente (Uruguay). Experta universitaria en Administración de la Educación, Convenio UruguayEspaña. Investigadora en la diversidad y la educación inclusiva en el sistema educativo. Inspectora departamental, Administración Nacional de Educación Pública (Uruguay).

${ }^{2}$ Doctora en Ciencias de la Educación, Licenciada en Ciencias de la Educación y Profesora de Grado Universitario en Ciencias de la Educación, Universidad Nacional de Cuyo (Argentina). Docente, Facultad de Filosofía y Letras, Universidad Nacional de Cuyo (Argentina). Investigadora en psicología de la educación, el aprendizaje autorregulado, la motivación o perspectiva temporal, los patrones de aprendizaje y los patrones temporales en estudiantes universitarios.

\section{Nota:}

Aprobación final del artículo, editora responsable Mag. Verónica Zorrilla de San Martín.

Contribución de autoría. La concepción del trabajo científico fue realizada por Nancy Núñez Soler y Mariela Lourdes González. La recolección, interpretación y análisis de datos estuvo a cargo de Nancy Núñez Soler. La redacción/revisión del manuscrito fue realizada por Nancy Núñez Soler y Mariela Lourdes González. Ambas autoras revisaron y aprobaron el contenido final.

' http://cep.edu.uy/index.php?option=com_content\&view=article\&id=1397\&ltemid=706

" http://www.ine.gub.uy/ 